\title{
PRODUÇÃO E QUALIDADE DA SERRAPILHEIRA DE TRÊS LEGUMINOSAS ARBÓREAS NATIVAS DO NORDESTE DO BRASIL
}

\author{
PRODUCTION AND QUALITY OF LITTER OF THREE LEGUMINOUS TREE NATIVE \\ OF THE NORTHEASTERN BRAZIL
}

\author{
Machado, F.A. ${ }^{1}$, Bezerra Neto, E. ${ }^{2 A}$, Nascimento, M. do P.S.C.B. ${ }^{3 A}$, Silva, L.M. ${ }^{2 B}$, \\ Barreto, L.P. ${ }^{2 C}$, Nascimento, H.T.S. ${ }^{3 B}$ e Leal, J.A. ${ }^{3 C}$
}

\begin{abstract}
1Universidade Estadual do Piauí. UESPI. Corrente-PI. Brasil. fmachado72@yahoo.com.br ²DepartamentodeQuímica.UFRPE.Recife-PE.Brasil.Aegidio@ufrpe.br; ${ }^{\circledR}$ lucieliom@bol.com.br; ${ }^{\circ}$ levy@ufrpe.br ${ }^{3}$ Embrapa Meio-Norte. Buenos Aires. Teresina-PI. Brasil. Asbona@cpamn.embrapa.br; Bhoston@cpamn. embrapa.br; 'Calcimar@cpamn.embrapa.br
\end{abstract}

\section{PaLAVRAS CHAVE ADICIONAIS}

Parkia platycephala. Caesalpinea ferrea. Samanea saman. Conservação de solo. Sistema silvipastoril.

\section{RESUMO}

O objetivo deste trabalho foi estudar a produção e qualidade da serrapilheira de três leguminosas arbóreas nativas do Nordeste do Brasil, a faveira (Parkia platycephala Benth.), o pau-ferro (Caesalpinea ferrea Mart. ex Tul.) e o bordão-develho (Samanea saman (Jack.) Merr.) visando a inserção destas em sistemas silvipastoris. Foi recolhido material depositado em coletores instalados sob a copa. As amostras coletadas foram separadas nas frações folíolo, miscelânea e vagem, que foram analisadas quanto aos teores de nitrogênio, fósforo e potássio. A produção média de serrapilheira no período do bordão-develho foi $542 \mathrm{~g} / \mathrm{m}^{2}$, da faveira, $311 \mathrm{~g} / \mathrm{m}^{2}$ e do pauferro, $594 \mathrm{~g} / \mathrm{m}^{2}$. As três espécies apresentaram sazonalidade de produção, com o bordão-develho concentrando a produção em agosto, a faveira de julho a outubro, e o pau-ferro de abril a agosto. Os teores de $\mathrm{P}$ nas três espécies foram baixos, com exceções para a fração vagem do bordão-de-velho $(0,21 \%)$ e frações miscelânea e vagem do pau-ferro, $0,14 \%$ e $0,16 \%$, respectivamente. Os teores de $\mathrm{K}$ variaram de $0,16 \%$, na miscelânea da faveira, a $0,65 \%$ na vagem do bordão-de-velho. Os teores de $\mathrm{N}$ variaram de 0,85\%, na miscelânea da faveira, a 2,13\% no folíolo do bordão-de-velho. As três espécies demonstraram potencial para conservação de

Recibido: 2-3-10. Aceptado: 7-11-11.

\section{AdDitiOnAL KEYWORDS}

Parkia platycephala. Caesalpinea ferrea. Samanea saman. Soil conservation. Silvipastoril system.

solo para compor sistemas silvipastoris.

\section{SUMMARY}

The objective of this work was to study the production and litter quality of three native trees legumes of northeast of Brazil, the faveira (Parkia platycephala Benth.), the pau-ferro (Caesalpinea ferrea Mart. ex Tul.) and bordão-de-velho (Samanea saman (Jack.) Merr.) aiming the inclusion of these species in silvipastoral systems. Samples were taken from material deposited in collectors installed under the canopy of individuals; the samples were separates in folioles, miscellaneous and pods. The average productions were: bordãode-velho, 542; faveira, 311 and pau-ferro, $594 \mathrm{~g} /$ $\mathrm{m}^{2}$. The three species presented seasonal production, with the bordão-de-velho concentrating the production in August, the faveira from July to October, and the pau-ferro from April to August. The $\mathrm{P}$ contents in the three species had been low, with exceptions for pods of bordão-develho $(0.21 \%)$ and miscellaneus and pods of pauferro ( 0.14 and $0.16 \%$, respectively). The contents of $\mathrm{K}$ varied from $0.16 \%$, in miscellaneus of faveira to $0.65 \%$ in pods of the bordão-de-velho. The contents of $\mathrm{N}$ varied from $0.85 \%$, in miscellaneus of faveira to $2.13 \%$ in folioles of bordão-de-velho.

Arch. Zootec. 61 (235): 323-334. 2012. 
The three species showed potential for soil conservation through the deposition of its litter, and for integration in silvipastoral systems.

\section{INTRODUÇÃO}

De acordo com Carvalho et al. (2001), a decomposição da serrapilheira depositada pelas árvores e posterior absorção dos nutrientes pode constituir importante via de transferência vegetação-solo, principalmente em solos de baixa fertilidade.

Em função da sua importância, tem-se procurado determinar o quanto as árvores podem contribuir para melhoria ou manutenção das condições físico-químico-biológicas do solo através da produção de serrapilheira e da maior estabilização da umidade e temperatura do solo. Em floresta tropical úmida de Pernambuco, foram obtidas elevadas produções de matéria seca de serrapilheira, da ordem de 8 toneladas anuais por hectare (Sampaio et al., 1988), que proporcionaram um aporte da ordem de $12 \mathrm{~kg} / \mathrm{ha} /$ ano de potássio e $3 \mathrm{~kg} / \mathrm{ha} / \mathrm{ano}$ de fósforo. Em mata decídua do Rio Grande do $\mathrm{Sul}$, as produções de matéria seca variaram de 7,8 t/ha/ano a 9,2 t/ha/ano (Cunha et al., 1993; König et al., 2002a). Nas regiões semiáridas, as produções de matéria seca são inferiores, cerca de 3,4 t/ha/ano (Kirmse, 1984; Carvalho, 2003). Na região atlântica da Colômbia, Giraldo et al. (1995) obtiveram produções de serrapilheira de $2,7 \mathrm{t} / \mathrm{ha} / \mathrm{ano}$ a $1,2 \mathrm{t} / \mathrm{ha} /$ ano em sistemas silvipastoris com três densidades diferentes de árvores nativas.

A deposição de serrapilheira tem impacto positivo na fertilidade do solo. Segundo Oliveira (1999), em condições de cerrado, os níveis de fertilidade sob as copas de pequi (Caryocar brasiliense Camb.) e baru (Dypterix alata Vog.) são superiores aos encontrados a pleno sol, proporcionando melhores condições para o desenvolvimento de Brachiaria decumbens. Na caatinga cearense, Araújo Filho (1995) concluiu que a diminuição da cobertura do estrato lenhoso para níveis inferiores a $30 \%$ da área compromete a produção do estrato herbáceo.

De acordo com Pott (1993), as espécies faveira (Parkia platycephala Benth.), pauferro (Caesalpinea férrea Mart. ex Tul.) e bordão-de-velho (Samanea saman (Jack.) Merr.), todas nativas do Nordeste do Brasil, têm potencial para compor sistemas silvipastoris nesta região.

O presente trabalho teve o objetivo de caracterizar a produção e composição da serrapilheira quanto a $\mathrm{N}, \mathrm{P}$ e $\mathrm{K}$ das arbóreas nativas do Nordeste: pau-ferro, bordão-develho e faveira, visando contribuir para geração de informações que viabilizem a inclusão dessas espécies em sistemas silvipastoris.

\section{MATERIAL E MÉTODOS}

Cada espécie, faveira, bordão-de-velho, e pau-ferro, foi avaliada em uma localidade diferente, de relevo plano e clima tipo AW', segundo a classificação de Köppen (Leprun, 1986). Segundo Nascimento et al. (1996), as três espécies são árvores nativas caducifólias da região da bacia do Rio Parnaíba, onde foram realizadas as observações, e historicamente são utilizadas como forrageiras.

As observações do bordão-de-velho foram realizadas no município de Campo Maior, estado do Piaúí/Brasil (PI), de $4^{\circ} 49^{\prime}$ sul de latitude e $42^{\circ} 11^{\prime}$ oeste de longitude. A precipitação pluviométrica média é de $1303 \mathrm{~mm} /$ ano, concentrada (85\%) no período de janeiro a junho, segundo dados médios de 70 anos (Brasil, 1990). O solo, de origem aluvial, apresenta classificação textural argila, caracterizado por bons índices de fertilidade (tabela I).

A faveira foi avaliada no município de Altos-PI, $5^{\circ} 02^{\prime}$ sul de latitude e $42^{\circ} 28^{\prime}$ oeste de longitude. A precipitação pluviométrica média é de $1240 \mathrm{~mm} /$ ano, concentrada (89\%) no período de janeiro a junho, segundo dados médios de 70 anos (Brasil, 1990). O solo possui classificação textural areia fran- 
ca, caracterizado por baixos pH e índices de fertilidade (tabela I).

As observações quanto ao pau-ferro foram realizadas na área do Centro de Pesquisa Agropecuária do Meio-Norte (CPAMN), município de Teresina-PI, $5^{\circ} 05^{\prime}$ sul de latitude e $42^{\circ} 49^{\prime}$ oeste de longitude. A precipitação média é de aproximadamente $1400 \mathrm{~mm} / \mathrm{ano}$, concentrada (83\%) no período de janeiro a junho, segundo dados médios de 70 anos (Brasil, 1990). O solo apresenta classificação textural argila, caracterizado por $\mathrm{pH}$ próximo da neutralidade e por bons índices de fertilidade (tabela I).

Foram selecionadas cinco plantas adultas de bordão-de-velho e de pau-ferro, e seis plantas adultas de faveira, de aspecto o mais uniforme possível entre si, isoladas de outras lenhosas, em comunidades naturalmente estabelecidas.

As árvores de bordão-de-velho encontravam-se na periferia de um campo agrícola, distante das linhas de cultivo aproximadamente 20 metros. As plantas de faveira encontravam-se em área cujo estrato herbáceo era de capim andropógon (Andropogon gayanus Kunth.), semeado entre as árvores há aproximadamente 10 anos. A área do pauferro é uma mata secundária com predominância de pau-ferro e ocorrência de algumas plantas de sabiá (Mimosa caesalpiniifolia
Benth.). No estrato herbáceo a cobertura é de capim-de-burro (Cynodon dactylon (L.) Pers.).

Todas as árvores utilizadas nas observações eram adultas e tiveram suas dimensões, altura e projeções de copa, mensuradas ao final da coleta de dados. Dois diâmetros da projeção da copa de cada árvore, em duas direções perpendiculares considerando-se o maior diâmetro, de forma a obter-se quatro ângulos de 90 graus, a partir da base do tronco das plantas, conforme metodologia proposta por Briscoe (1990), utilizando-se uma trena de 50 metros. A área de projeção de copa foi estimada utilizando-se as medidas dos diâmetros e considerando que esta tinha a forma elíptica. A área da projeção das copas foi utilizada para as estimativas de produção de serrapilheira por árvore, multiplicando-se produção encontrada por $\mathrm{m}^{2}$ pela área da projeção da copa. Visando caracterizar os indivíduos também foi estimada a altura de copa com o auxílio de um clinômetro.

Foram instalados sob as copas de cada árvore, dois coletores de formato quadrado com área de um metro quadrado, alocados ao acaso a aproximadamente um metro do caule da planta. Os coletores eram constituídos de uma armação de ferro e uma tela plástica de $1 \mathrm{~mm}$ de malha, visando reter a

Tabela I. Características químicas do solo ${ }^{I}$ das áreas de bordão-de-velho (Samanea saman), em Campo Maior-PI, da faveira (Parkia platycephala), em Altos-PI, e do pau-ferro (Caesalpinea ferrea), em Teresina-PI. (Characteristics of soil in sites of bordão-de-velho (Samanea saman) in Campo Maior, faveira (Parkia platycephala) in Altos, and pau-ferro (Caesalpinia ferrea) in Teresina, Piauí state/Brazil).

\begin{tabular}{lccccccccr}
\hline Espécie & $\mathrm{MO}^{2}$ & $\mathrm{pH}^{3}$ & $\mathrm{P}^{4}$ & $\mathrm{~K}^{5}$ & $\mathrm{Ca}^{5}$ & $\mathrm{Mg}^{5}$ & $\mathrm{Na}^{5}$ & $\mathrm{Al}^{5}$ & $\mathrm{H}+\mathrm{Al}^{5}$ \\
\hline Bordão- & & & & & & & & & \\
de-velho & 2,13 & 6,00 & 5,12 & 0,32 & 4,07 & 4,10 & 0,09 & 0,30 & 2,26 \\
Faveira & 1,62 & 5,16 & 4,46 & 0,16 & 0,77 & 0,29 & 2,74 & 0,15 & 0,56 \\
Pau-ferro & 2,32 & 6,08 & 3,82 & 0,38 & 4,17 & 4,14 & 0,07 & 0,42 & 1,88 \\
\hline
\end{tabular}

${ }^{1}$ Amostras obtidas a pleno sol em solos que não estavam sob influência da copa das árvores. Análises realizadas no Laboratório de Química e Fertilidade do Solo da Embrapa Meio-Norte.

$2 \% ;{ }^{3} \mathrm{em} \mathrm{H}_{2} \mathrm{O} ;{ }^{4} \mathrm{mg} / \mathrm{dm}^{3} ;{ }^{5} \mathrm{cmol}_{\mathrm{c}} / \mathrm{dm}^{3}$. 


\section{MACHADO, BEZERRA NETO, NASCIMENTO, SILVA, BARRETO, NASCIMENTO ELEAL}

serrapilheira e drenar a água das chuvas.

O período de coleta de serrapilheira variou entre as três espécies, uma vez que houve variação no período de queda de serrapilheira entre as espécies. Para o bordão-de-velho, o período de observação compreendeu os meses de abril a outubro de 2004 (sete meses), para a faveira, de abril a novembro (oito meses), e para o pau-ferro, de abril a setembro (seis meses). As coletas foram realizadas quinzenalmente, compreendendo o recolhimento total do material contido nos coletores, e desprezados os insetos, ramos lignificados de diâmetro superior a seis milímetros e demais impurezas.

O material coletado foi acondicionado em sacos de papel e posteriormente colocado em estufa de ventilação forçada a $65^{\circ} \mathrm{C}$ por 72 horas. Após a secagem, as amostras foram pesadas e separadas em suas frações de folíolos, vagens e miscelânea. A fração miscelânea era constituída de pedicelos, pecíolos, inflorescências abortadas, pedaços de cascas. Cada fração foi pesada em balança eletrônica de 0,1 grama de precisão e moída em moinho de facas, munido de malha de um milímetro, e acondicionada em sacos plásticos fechados.

Todas as frações vegetais foram analisadas para $\mathrm{N}, \mathrm{P}$ e $\mathrm{K}$, no laboratório de Nutrição Mineral de Plantas do Departamento de Química da UFRPE. A determinação analítica do nitrogênio foi efetuada pelo método de Kjeldahl, em que as amostras foram digeridas por ácido sulfúrico em presença de catalisadores. Para a análise de $\mathrm{P}$ e K, primeiramente digeriu-se a amostra com ácido nítrico e ácido perclórico. O teor de $\mathrm{P}$ foi quantificado em espectrofotômetro de emissão e o teor de $\mathrm{K}$ em fotômetro de chama, conforme preceituam Bezerra Neto e Barreto (2004).

Foram determinadas médias e intervalos de confiança, com a percentagem da população de respostas dentro do intervalo de confiança definido em $95 \%(\alpha=0,05)$, para os dados de produção e composição química das diversas frações da serrapilheira das três espécies, conforme preconizado por Sampaio (1998).

\section{RESULTADOS}

As produções médias de serrapilheira total do bordão-de-velho (sete meses de coleta), faveira (oito meses de coleta) e pauferro (seis meses de coleta) durante o período experimental foram $542 \mathrm{~g} / \mathrm{m}^{2}, 311 \mathrm{~g} / \mathrm{m}^{2} \mathrm{e}$ $594 \mathrm{~g} / \mathrm{m}^{2}$, respectivamente. O bordão-develho concentrou a queda de serrapilheira em agosto, a faveira de julho a outubro, enquanto que o pau-ferro nos meses de maio a julho (figura 1). No mês de outubro as plantas de bordão-de-velho estavam totalmente desfolhadas e com uma lenta rebrota. Convém ressaltar que as árvores das três espécies encontravam-se em ambientes distintos, e que estes comentários objetivam unicamente descrever os resultados, e não comparar as três diferentes espécies. Observa-se também que as produções de serrapilheira para o bordãode-velho e a faveira concentraram-se em épocas já configuradas como secas (figura 2).

A fração folíolo do bordão-de-velho apresentou aumento gradativo de abril a agosto, quando apresentou seu mais alto valor $\left(59,57 \mathrm{~g} / \mathrm{m}^{2} / \mathrm{mês}\right)$, apresentando queda em setembro e chegando a zero em outubro. A fração miscelânea da serrapilheira teve produção semelhante em abril e maio, respectivamente 7,58 e $6,63 \mathrm{~g} / \mathrm{m}^{2} / \mathrm{mês}$, aumentando gradativamente até o mês de agosto, quando foi máxima $\left(35,35 \mathrm{~g} / \mathrm{m}^{2} / \mathrm{mês}\right)$, caindo a partir de então. A produção da fração vagem deu-se nos meses de julho a setembro, sendo fortemente concentrada em agosto (tabela II). A fração vagem contribuiu com $47,75 \%$, os folíolos com $31,17 \%$ e a miscelânea com $21,08 \%$ do total de serrapilheira do bordão-de-velho. O elevado peso das vagens com relação às demais frações provavelmente condicionou este último comportamento.

A produção das frações folíolo e miscelânea da faveira foi baixa de abril a 


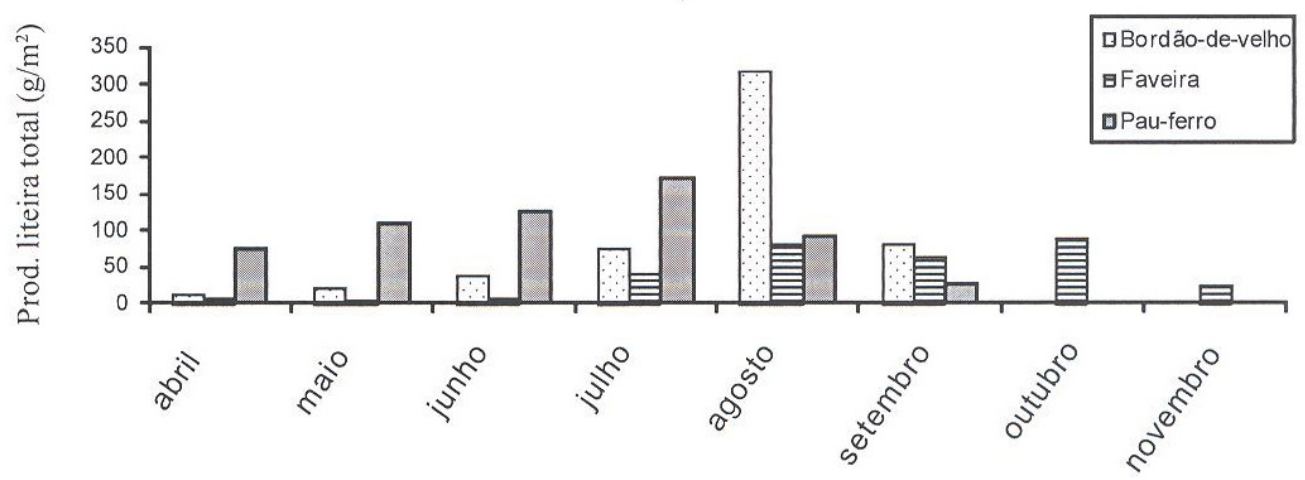

Figura 1. Produção de serrapilheira total $\left(\mathrm{g} / \mathrm{m}^{2}\right)$ pelo bordão-de-velho (Samanea saman), pela faveira (Parkia platycephala) e pelo pau-ferro (Caesalpinea ferrea ), em suas respectivas áreas. (Production of total litter $\left(\mathrm{g} / \mathrm{m}^{2}\right)$ for bordão-de-velho (Samanea saman), faveira (Parkia platycephala) and pau-ferro (Caesalpinia ferrea), in their respective sites).

junho, e alta em agosto, voltando a cair novamente em setembro. Algumas das plantas em observação só apresentaram queda de folíolos em outubro, o que levou a uma elevação neste mês, voltando a ter baixas produções em novembro, quando as plantas estavam com a folhagem renovada. Inicialmente, a fração miscelânea também apresentou produção reduzida, com crescimento gradativo, em função da queda de pecíolos e principalmente de inflorescências abortadas, o que contribuiu para sua maior produção total em relação às demais frações. A produção máxima de miscelânea ocorreu no mês de outubro. A produção da fração vagem foi fortemente concentrada nos meses de setembro e outubro, com maior produção em setembro (tabela III). A contribuição das diferentes frações para a composição total da serrapilheira foi $56,21 \%$ para miscelânea, $29,45 \%$ para folíolo e $14,34 \%$ para vagem. Torna-se importante salientar a pequena dimensão dos folíolos da espécie, o que provavelmente diminuiu a contribuição desta fração quando relacionado com a miscelânea, que por sua vez era constituída por ramos mais pesados em algumas avaliações.

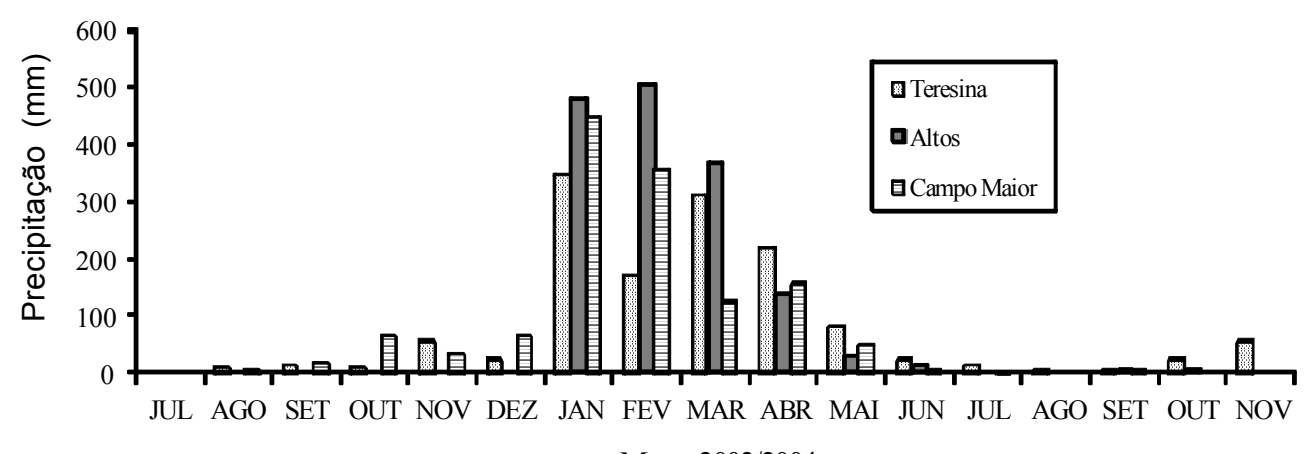

Meses 2003/2004

Figura 2. Precipitação pluviométrica nos municípios de Campo Maior, Altos e Teresina, estado do Piaui/Brasil. (Rainfall in the cities of Campo Maior, Altos and Teresina, Piaui state/Brazil). 
MACHADO, BEZERRA NETO, NASCIMENTO, SILVA, BARRETO, NASCIMENTO E LEAL

Tabela II. Produções médias ( \pm intervalos de confiança) das frações da serrapilheira $\left(\mathrm{g} / \mathrm{m}^{2}\right)$ de bordão-de-velho (Samanea saman), em Campo Maior, estado do Piaui/Brasil. (Average yields ( \pm confidence intervals) of litter fractions $\left(\mathrm{g} / \mathrm{m}^{2}\right)$ of bordão-de-velho (Samanea saman) in Campo Maior, Piauí state/Brazil).

\begin{tabular}{lccccccc}
\hline Frações & Abril & Maio & Junho & Julho & Agosto & Setembro & Total \\
\hline Folíolo & $5,2 \pm 2,1$ & $14,6 \pm 6,0$ & $22,7 \pm 8,9$ & $40,8 \pm 15,7$ & $59,8 \pm 30,1$ & $25,8 \pm 25,3$ & 169,0 \\
Miscelânea & $7,6 \pm 4,4$ & $6,6 \pm 2,9$ & $12,8 \pm 4,7$ & $22,1 \pm 11,7$ & $35,4 \pm 15,7$ & $29,9 \pm 14,0$ & 114,3 \\
Vagem & - & - & - & $12,9 \pm 2,4$ & $221,9 \pm 143,5$ & $24,1 \pm 18,0$ & 258,9 \\
\hline
\end{tabular}

O pau-ferro apresentou maior produção de serrapilheira das frações folíolo e miscelânea em abril e maio, meses chuvosos. A produção de vagens ocorreu nos meses de junho a setembro, sendo que no mês de setembro ocorreu uma diminuição significativa na produção desta fração (tabela IV). Do total de serrapilheira do pau-ferro, $57,52 \%$ foi de vagem, $24,87 \%$ de folíolo e $17,61 \%$ de miscelânea. Assim como o bordão-de-velho, o elevado peso das vagens com relação às demais frações provavelmente condicionou este último comportamento.

Com relação ao teor de nutrientes minerais, as frações folíolo e miscelânea do bordão-de-velho apresentaram decréscimo nos teores de $\mathrm{P}$ durante o período de observação, notadamente a partir de julho. $\mathrm{O}$ teor de K não apresentou grande variação nas frações folíolo e miscelânea no decorrer do período, enquanto que nas vagens o teor deste nutriente mineral foi superior nos meses de julho e agosto, 0,60 e $0,74 \%$ respectivamente, em relação a setembro (0,29\%). O conteúdo de nitrogênio foi mais elevado nos meses de maio e junho para folíolo e julho para vagem. Na fração miscelânea, o teor de $\mathrm{N}$ foi menor no mês de setembro $(0,94 \%)$ (tabela V).

O teor de P da fração folíolo da faveira apresentou variação ao longo do período, apresentando valores mais elevados em abril e maio $(0,09 \%)$ e valores mais baixos em outubro e novembro $(0,03 \%)$. O teor de $\mathrm{K}$ nos folíolos variou, com valores baixos em abril $(0,16 \%)$, elevado em maio $(0,78 \%)$, diminuindo a partir deste mês e tendo seus valores mais baixos em setembro, outubro e novembro. Durante os meses de abril a agosto, o teor de $\mathrm{N}$ nos folíolos mostrou-se estável com uma nítida queda nos meses de setembro a novembro. O teor de fósforo na fração miscelânea da faveira comportou-se de forma semelhante ao teor deste nutriente mineral na fração folíolo, isto é, apresentou valor mais elevado no mês de maio $(0,05 \%)$ e mais baixo nos meses de outubro e novembro. $\mathrm{O}$ teor de $\mathrm{K}$ teve seu valor mais baixo no mês de abril (0,07\%), subiu a partir de maio até atingir seus valores mais elevados em junho e julho $(0,26$ e $0,30 \%$ respec-

Tabela III. Produções médias ( \pm intervalos de confiança) das frações da serrapilheira $(\mathrm{g} / \mathrm{m} 2)$ de faveira (Parkia platycephala), em Altos, estado do Piauí/Brasil. (Average yields ( \pm confidence intervals) of litter fractions $\left(\mathrm{g} / \mathrm{m}^{2}\right)$ of faveira (Parkia platycephala) in Altos, Piauí state/ Brazil).

\begin{tabular}{lccc}
\hline & Folíolo & Miscelânea & Vagem \\
\hline Abril & $1,8 \pm 0,6$ & $3,6 \pm 1,1$ & - \\
Maio & $1,8 \pm 0,7$ & $2,3 \pm 1,3$ & - \\
Junho & $2,5 \pm 1,4$ & $3,9 \pm 2,5$ & - \\
Julho & $11,1 \pm 15,9$ & $30,2 \pm 21,1$ & - \\
Agosto & $47,0 \pm 44,0$ & $33,7 \pm 20,3$ & - \\
Setembro & $4,8 \pm 2,5$ & $26,3 \pm 8,43$ & $31,1 \pm 51,98$ \\
Outubro & $16,3 \pm 10,6$ & $62,5 \pm 16,3$ & $9,9 \pm 6,69$ \\
Novembro & $6,5 \pm 11,75$ & $12,7 \pm 19,67$ & $3,7 \pm 7,19$ \\
Total & 91,8 & 175,2 & 44,7 \\
\hline
\end{tabular}


Tabela IV. Produções médias ( \pm intervalos de confiança) das frações da serrapilheira ( $\mathrm{g}$ / $\mathrm{m}^{2}$ ) de pau-ferro (Caesalpinea férrea) em Teresina, estado do Piaui/Brasil. (Average yields ( \pm confidence intervals) of litter fractions $\left(\mathrm{g} / \mathrm{m}^{2}\right)$ of pau-ferro (Caesalpinia ferrea) in Teresina, Piaui state/ Brazil).

\begin{tabular}{lccccccc}
\hline Frações & Abril & Maio & Junho & Julho & Agosto & Setembro & Total \\
\hline Folíolo & $42,3 \pm 26,9$ & $62,4 \pm 28,4$ & $22,7 \pm 15,9$ & $4,9 \pm 1,5$ & $4,8 \pm 4,7$ & $2,8 \pm 0,5$ & 147,8 \\
Miscelânea & $23,1 \pm 7,6$ & $46,1 \pm 7,1$ & $14,6 \pm 4,8$ & $8,5 \pm 7,9$ & $6,4 \pm 3,8$ & $2,9 \pm 1,2$ & 104,6 \\
Vagem & - & - & $84,3 \pm 79,6$ & $159,0 \pm 98,1$ & $79,2 \pm 79,0$ & $19,3 \pm 21,9$ & 341,8 \\
\hline
\end{tabular}

tivamente), quando voltou a cair. Quanto ao teor de N, a miscelânea apresentou-se estável entre os meses de abril a julho, mais elevado em agosto, quando as amostras continham muitas inflorescências, havendo queda daí em diante (tabelaVI).

Foram observadas pequenas variações nos teores de $\mathrm{P}$ da fração folíolo do pauferro, com maior teor no mês de julho $(0,10 \%)$. O teor de potássio na fração folíolo mostrouse estável ao longo do período de observação, enquanto que o teor de nitrogênio teve seu valor mais elevado no mês de abril $(1,99 \%)$, diminuindo gradativamente até o mês de setembro. A fração miscelânea apresentou grandes variações na sua composição quanto a $\mathrm{P}$ e $\mathrm{K}$, sem um comportamento padrão consistente. No entanto, o teor de potássio foi mais elevado no início do período, e o de fósforo no final, em agosto, antes da queda em setembro. $\mathrm{O}$ teor de nitrogênio na fração miscelânea foi mais elevado no mês de abril (1,89\%), diminuindo gradativamente até o mês de setembro $(0,87 \%)$. A fração vagem não apresentou grande variação nos teores de fósforo nem de nitrogênio, enquanto que o teor de potássio teve seu valor mais elevado em agosto $(0,56 \%)$, caindo em setembro para $0,29 \%$, seu valor mínimo (tabela VII).

Tabela $\boldsymbol{V}$. Teores médios ( \pm intervalos de confiança) de nitrogênio, fósforo e potássio nas frações da serrapilheira (\%) para o bordão-de-velho (Samanea saman) em Campo Maior, estado do Piauí/Brasil. (Average ( \pm confidence intervals) levels of nitrogen, phosphorus and potassium in the fractions of litter (\%) for the bordão-de-velho (Samanea saman) in Campo Maior, Piauí state/Brazil).

\begin{tabular}{ccccccc}
\hline \multicolumn{2}{c}{ Abril } & Maio & Junho & Julho & Agosto & Setembro \\
\hline Folíolo & & & & & & \\
P & $0,07 \pm 0,01$ & $0,06 \pm 0,01$ & $0,06 \pm 0,03$ & $0,04 \pm 0,04$ & $0,03 \pm 0,01$ & $0,02 \pm 0,02$ \\
K & $0,20 \pm 0,01$ & $0,16 \pm 0,06$ & $0,17 \pm 0,06$ & $0,13 \pm 0,05$ & $0,20 \pm 0,11$ & $0,23 \pm 0,051$ \\
N & $2,12 \pm 0,27$ & $2,63 \pm 0,21$ & $2,67 \pm 0,21$ & $2,38 \pm 0,08$ & $2,08 \pm 0,19$ & $1,09 \pm 0,11$ \\
Miscelânea & & & & & & \\
P & $0,09 \pm 0,01$ & $0,11 \pm 0,03$ & $0,12 \pm 0,01$ & $0,04 \pm 0,01$ & $0,05 \pm 0,04$ & $0,04 \pm 0,003$ \\
K & $0,25 \pm 0,07$ & $0,27 \pm 0,08$ & $0,32 \pm 0,13$ & $0,25 \pm 0,16$ & $0,35 \pm 0,12$ & $0,42 \pm 0,12$ \\
N & $2,14 \pm 0,35$ & $2,34 \pm 0,23$ & $2,07 \pm 0,13$ & $2,02 \pm 0,32$ & $1,80 \pm 0,15$ & $0,94 \pm 0,27$ \\
Vagem & & - & - & & & \\
P & - & - & - & $0,20 \pm 0,19$ & $0,20 \pm 0,20$ & $0,06 \pm 0,005$ \\
K & - & - & - & $2,67 \pm 0,19$ & $1,88 \pm 0,18$ & $1,07 \pm 0,05$ \\
N & - & - & & & & \\
\hline
\end{tabular}


Tabela VI. Teores (土 intervalos de confiança) de nitrogênio, fósforo e potássio nas frações da serrapilheira (\%) para faveira (Parkia platycephala) em Altos, estado do Piaui/Brasil. (Levels ( \pm confidence intervals) of nitrogen, phosphorus and potassium in the fractions of litter $(\%)$ and their respective confidence intervals, for faveira (Parkia platycephala) in Altos, Piauí state/Brazil).

\begin{tabular}{ccccccccc}
\hline \multicolumn{1}{c}{ Abril } & Maio & Junho & Julho & Agosto & Setembro & Outubro & Novembro \\
\hline Folíolo & & & & & & & \\
P & $0,09 \pm 0,11$ & $0,09 \pm 0,02$ & $0,04 \pm 0,005$ & $0,06 \pm 0,01$ & $0,07 \pm 0,02$ & $0,04 \pm 0,006$ & $0,03 \pm 0,01$ & $0,03 \pm 0,01$ \\
K & $0,16 \pm 0,01$ & $0,78 \pm 0,05$ & $0,33 \pm 0,07$ & $0,38 \pm 0,16$ & $0,50 \pm 0,04$ & $0,15 \pm 0,04$ & $0,17 \pm 0,01$ & $0,18 \pm 0,01$ \\
N & $1,65 \pm 0,08$ & $1,78 \pm 0,07$ & $1,73 \pm 0,15$ & $1,73 \pm 0,06$ & $1,71 \pm 0,19$ & $1,07 \pm 0,05$ & $1,04 \pm 0,06$ & $1,04 \pm 0,04$ \\
Miscelânea & & & & & & & \\
P & $0,02 \pm 0,01$ & $0,05 \pm 0,01$ & $0,04 \pm 0,01$ & $0,04 \pm 0,01$ & $0,02 \pm 0,01$ & $0,02 \pm 0,001$ & $0,01 \pm 0,0010,01 \pm 0,001$ \\
K & $0,07 \pm 0,03$ & $0,12 \pm 0,02$ & $0,26 \pm 0,09$ & $0,30 \pm 0,06$ & $0,19 \pm 0,02$ & $0,11 \pm 0,02$ & $0,13 \pm 0,05$ & $0,14 \pm 0,04$ \\
N & $1,06 \pm 0,14$ & $1,05 \pm 0,12$ & $1,03 \pm 0,12$ & $1,11 \pm 0,16$ & $1,44 \pm 0,15$ & $0,55 \pm 0,07$ & $0,56 \pm 0,03$ & $0,54 \pm 0,02$ \\
\hline
\end{tabular}

As frações da serrapilheira do bordãode-velho apresentaram diferenças quanto à composição, sendo as vagens mais ricas em P e K, seguidas da miscelânea e folíolos, sendo os maiores teores de nitrogênio apresentados pela fração folíolo (tabela VIII). A fração folíolo da faveira apresentou melhor composição quanto a $\mathrm{P}, \mathrm{K}$ e $\mathrm{N}$ do que a fração miscelânea (tabela VIII). Com relação às diferentes frações da serrapilheira do pau-ferro, observa-se que a fração misce- lânea obteve valores mais altos de fósforo e potássio e nitrogênio, enquanto que nitrogênio foi mais elevado na fração folíolo. A fração vagem apresentou teores mais altos de $\mathrm{P}$ e mais baixos de $\mathrm{K}$ e N (tabela VIII).

As plantas de bordão-de-velho observadas possuíam uma altura de copa que variou de 5,2 a 7,9 metros, maior diâmetro de copa com variação de 13,1 a 21,1 metros e menor diâmetro no intervalo de 12,1 a 16,9

Tabela VII. Teores médios ( \pm intervalos de confiança) de nitrogênio, fósforo e potássio nas frações da serrapilheira (\%) e seus respectivos intervalos de confiança, para o pau-ferro (Caesalpinea férrea) em Teresina, estado do Piaui/Brasil. (Average ( \pm confidence intervals) levels of nitrogen, phosphorus and potassium in the fractions of litter (\%) and their respective confidence intervals for the pau-ferro (Caesalpinia ferrea) in Teresina, Piaui state/Brazil).

\begin{tabular}{|c|c|c|c|c|c|c|}
\hline & Abril & Maio & Junho & Julho & Agosto & Setembro \\
\hline \multicolumn{7}{|c|}{ Folíolo } \\
\hline$P$ & $0,07 \pm 0,03$ & $0,07 \pm 0,02$ & $0,07 \pm 0,02$ & $0,10 \pm 0,02$ & $0,07 \pm 0,03$ & $0,06 \pm 0,005$ \\
\hline $\mathrm{K}$ & $0,36 \pm 0,10$ & $0,41 \pm 0,07$ & $0,28 \pm 0,05$ & $0,27 \pm 0,07$ & $0,25 \pm 0,05$ & $0,41 \pm 0,15$ \\
\hline $\mathrm{N}$ & $1,99 \pm 0,50$ & $1,51 \pm 0,32$ & $1,52 \pm 0,15$ & $1,43 \pm 0,10$ & $1,44 \pm 0,30$ & $1,29 \pm 0,11$ \\
\hline \multicolumn{7}{|c|}{ Miscelânea } \\
\hline $\mathrm{P}$ & $0,14 \pm 0,018$ & $0,13 \pm 0,03$ & $0,15 \pm 0,02$ & $0,16 \pm 0,04$ & $0,20 \pm 0,04$ & $0,03 \pm 0,003$ \\
\hline $\mathrm{K}$ & $0,75 \pm 0,02$ & $0,81 \pm 0,07$ & $0,41 \pm 0,01$ & $0,32 \pm 0,05$ & $0,64 \pm 0,13$ & $0,24 \pm 0,02$ \\
\hline $\mathrm{N}$ & $1,89 \pm 0,57$ & $1,46 \pm 0,50$ & $1,14 \pm 0,06$ & $1,27 \pm 0,13$ & $0,99 \pm 0,21$ & $0,87 \pm 0,07$ \\
\hline \multicolumn{7}{|c|}{ Vagem } \\
\hline $\mathrm{P}$ & - & - & $0,20 \pm 0,04$ & $0,16 \pm 0,03$ & $0,14 \pm 0,03$ & $0,12 \pm 0,12$ \\
\hline $\mathrm{K}$ & - & - & $0,43 \pm 0,17$ & $0,39 \pm 0,13$ & $0,56 \pm 0,08$ & $0,29 \pm 0,09$ \\
\hline $\mathrm{N}$ & - & - & $1,24 \pm 0,11$ & $1,21 \pm 0,23$ & $1,61 \pm 0,35$ & $1,23 \pm 0,19$ \\
\hline
\end{tabular}

Archivos de zootecnia vol. 61, núm. 235, p. 330. 
Tabela VIII. Composição química das frações da serrapilheira (\%) de bordão-develho (Samanea saman), de faveira (Parkia platycephala) e de pau-ferro (Caesalpinea férrea). (Chemical composition of fractions of litter (\%) of bordão-de-velho (Samanea saman), faveira (Parkia platycephala) and pau-ferro (Caesalpinia ferrea).

\begin{tabular}{cccc}
\hline & Folíolo & Miscelânea & Vagem \\
\hline Bordão-de-velho & & & \\
N & 0,04 & 0,06 & 0,21 \\
P & 0,18 & 0,33 & 0,69 \\
K & 2,13 & 1,70 & 1,84 \\
Faveira & & & \\
N & 0,06 & - & 0,02 \\
P & 0,38 & - & 0,17 \\
K & 1,51 & & 0,85 \\
Pau-ferro & & & \\
N & 0,07 & 0,14 & 0,16 \\
P & 0,34 & 0,65 & 0,43 \\
K & 1,56 & 1,41 & 1,31 \\
\hline
\end{tabular}

metros. Os indivíduos analisados de pauferro possuíam uma altura de copa que variou de 1,7 a 4,5 metros, diâmetro maior de copa que variou de 7,3 a 9,1 metros e menor diâmetro no intervalo de 4,8 a 7,3 metros. As plantas analisadas de faveira possuíam uma altura de copa que variou de 6,2 a 13,1 metros, maior diâmetro de copa que variou de 12,4 a 21,4 metros e menor diâmetro de 11,9 a 19,8 metros.

\section{DISCUSSÃO}

As produções de matéria seca na serrapilheira do bordão-de-velho e do pauferro foram superiores aos $301 \mathrm{~g} / \mathrm{m}^{2} /$ ano e $309 \mathrm{~g} / \mathrm{m}^{2} /$ ano encontrados, respectivamente, para baru (Dypterix alata Vog.) e pequi (Caryocar brasiliense Camb.), enquanto que a faveira foi bastante próxima das encontradas para estas espécies (Oliveira, 1999). Salienta-se que a faveira é planta típica de cerrado (Braga, 1960), e desenvolveu-se em condições de baixa fertilidade e $\mathrm{pH}$, a exemplo do baru e pequi citados anteriormente. As produções do bordãode-velho e pau-ferro foram superiores às encontradas por Ramos (1994), que obteve produção média para o sub-arbusto feijãoguandu (Cajanus cajan (L.) Mills.) de $352 \mathrm{~g} /$ $\mathrm{m}^{2} /$ ano, considerada pelo autor como alta e com elevado potencial para melhoramento de solo.

As maiores produções de serrapilheira para o bordão-de-velho e a faveira foram em época já configurada como seca (figura 2), concordando com Oliveira (1999), que também observou a concentração na queda de serrapilheira no período seco para o baru e pequi, em condições de cerrado. A sazonalidade de produção de serrapilheira nas regiões tropicais, com maiores produções nas épocas secas, é fato comum e observado em diversos ecossistemas dessas regiões, conforme trabalhos de Carvalho(2003), em área de caatinga, Borém e Ramos (2002) para mata atlântica e König et al. (2002a) e Cunha et al. (1993) para floresta estacional decídua. Cunha et al. (1993) relacionaram este efeito com extremos climáticos, principalmente de temperatura e precipitação pluviométrica, estando vinculado com mecanismos de defesa dos vegetais sob estas condições climáticas.

O comportamento semelhante entre as frações folíolo e miscelânea do bordão-develho, exceto nos meses de abril e setembro, pode ser explicado pelo fato desta última ser constituída principalmente de pecíolos. No mês de abril, a fração miscelânea apresentava alguns galhos finos em algumas repetições, que provavelmente elevaram o seu peso, enquanto que em setembro esta maior proporção da miscelânea pode ser devido a pequena queda de folíolos, pois as plantas apresentavam-se quase que totalmente desfolhadas. Segundo Justiniano e Fredericksen (2000) a deciduidade de arbóreas é comum em espécies de regiões de déficit hídrico durante longo período do ano, com espécies que perdem as folhas já no final da estação chuvosa enquanto outras as perdem 
durante o período seco, como foi o caso do bordão-de-velho.

Segundo Bulhão e Figueiredo (2002) a queda concentrada de folhas com rápida renovação dos ramos pela faveira, do meio ao fim do período seco, é característica da espécie em região de cerrado do norte do Maranhão. De acordo com Nascimento et al., 1996, a faveira apresenta renovação total da sua copa anualmente e as folhas caídas nutrem e protegem o solo na área de projeção de copa. Quanto às menores produções dos folíolos, exceto no mês de agosto, ela pode ser atribuída as suas reduzidas dimensões, chegando inclusive a haver perdas nas coletas, em função da passagem dos mesmos pela malha da tela do coletor, necessitando de cuidados durante o procedimento. A queda das três frações ocorreu de forma bastante desigual entre os indivíduos no mês de novembro, havendo plantas que apresentaram queda enquanto outras não.

Aos resultados obtidos para a concentração na queda de folhas pelo pau-ferro, observa-se que estes coincidem com os de Machado et al. (1997), segundo os quais a espécie perde suas folhas na transição do período chuvoso e seco, havendo formação de novas folhas neste período. As produções antecipadas dos folíolos e miscelânea já em abril a junho, meses de acumulado de precipitação superior a $300 \mathrm{~mm}$, sugerem uma maior taxa de decomposição deste material que nas outras duas espécies estudadas, uma vez que a disponibilidade de umidade é condicionante da taxa de decomposição (Silva e Resck, 1998).

A semelhança observada na composição das frações folíolos e miscelânea podem ser explicadas pela predominância de pedicelos nesta última fração. A variação nos teores de $\mathrm{N}$ e $\mathrm{P}$ e a manutenção nos do $\mathrm{K}$ durante o período também foram observados por König et al. (2002 b), em mata decídua do Rio Grande do Sul.

Observou-se também a presença de material mais tenro nos folíolos da faveira, o que pode explicar os maiores de teores dos elementos nesta fração da serrapilheira.

Segundo Menezes et al. (2002), as serrapilheiras de algaroba (Prosopis juliflora (SW.) DC.) e de juazeiro (Ziziphus joazeiro Mart.), em condições de semi-árido de Pernambuco, apresentaram 0,13\% e $0,09 \%$ de $\mathrm{P}$ e $2,46 \%$ e $2,32 \%$ de $\mathrm{N}$, respectivamente. Os teores de $\mathrm{P}$ obtidos neste trabalho, nas três espécies e suas frações, foram inferiores, com exceções para vagens do bordão-de-velho $(0,21 \%)$ e frações miscelânea e vagem do pau-ferro, $0,14 \%$ e $0,16 \%$, respectivamente. Os teores de $\mathrm{N}$ obtidos nas três espécies e respectivas frações foram inferiores aos da algaroba e juazeiro.

Quanto às medidas das copas das árvores de faveira, diâmetros e altura de copa, estas foram semelhantes às encontradas no município de Amarante (estado do Piauí), de 15,0 m e 9,2 metros para maior e menor diâmetro, respectivamente, e 10,6 metros de altura de copa, e de Teresina (Piauí), de 25,2 m e 15,2 metros para maior e menor diâmetro, respectivamente, e 18,1 metros de altura de copa (Embrapa, 1989).

Convém lembrar que, segundo Castelo Branco (2001), os solos das pastagens nativas do norte do Piauí, onde foram realizadas as observações, apresentam baixos níveis de fertilidade quanto aos teores de matéria orgânica, $\mathrm{P}$ e K, portanto, os aportes de nutrientes proporcionados pelas serrapilheiras das espécies, apesar de baixos, quando comparados aos de matas fechadas, podem contribuir para a reciclagem e, de alguma forma, para o retorno dos nutrientes para camadas mais profundas do solo.

Finalizando, as produções de serrapilheira do bordão-de-velho, da faveira, e do pau-ferro, aliadas aos teores de nitrogênio, fósforo e potássio encontrados, demonstram o potencial das espécies para conservação de solo, podendo-se considerar a inclusão dessas espécies em sistemas silvipastoris na região considerada. 
PRODUÇÃO E QUALIDADE DA SERRAPILHEIRA DE TRÊS LEGUMINOSAS ARBÓREAS

\section{BIBLIOGRAFIA}

Araújo Filho, J.A. 1995. Manipulação da vegetação lenhosa da caatinga para fins pastoris. EmbrapaCNPC. Sobral, CE. Circular Técnica, 11. $18 \mathrm{pp}$.

Bezerra Neto, E. e Barreto, L.P. 2004. Métodos de análises químicas em plantas. $1^{\text {a }}$ ed. UFRPE. Recife. 149 pp.

Borém, R.A.T. e Ramos, D.P. 2002. Variação estacional e topográfica de nutrientes na serapilheira de um fragmento de mata atlântica. Cerne, 8: 42-59.

Braga, R. 1960. Plantas do Nordeste, especialmente do Ceará. $2^{\mathrm{a}}$ ed. Imprensa Oficial. Fortaleza. $540 \mathrm{pp}$.

Briscoe, C.B. 1990. Manual de ensayos de campo com arboles de usos multiples. Winrock International Institute for Agricultural Development. Série de red de investigacion sobre arboles de uses multiples. Manual $n^{\circ} 3$. Arlington. $143 \mathrm{pp}$.

Bulhão, C.F. e Figueiredo, P.S. 2002. Fenologia de leguminosas arbóreas em uma área de cerrado marginal no nordeste do Maranhão. Rev Bras Bot, 25: 361-369.

Brasil. 1990. Dados pluviométricos mensais do Nordeste. SUDENE-DPG-PRN-HME. Estado do Piauí. Recife. 236 pp.

Carvalho, F.C. de. 2003. Sistema de produção agrosilvipastoril para região semi-árida do Nordeste do Brasil. Tese (Doutorado). Universidade Federal de Viçosa. Viçosa, MG. 77 pp.

Carvalho, M.M., Xavier, D.F. e Alvim, M.J. 2001. Uso de leguminosas arbóreas na recuperação e sustentabilidade de pastagens cultivadas. In: Carvalho, M.M., Alvim, M.J., Carneiro, J.C. Sistemas agroflorestais pecuários: opções de sustentabilidade para áreas tropicais $e$ subtropicais. Embrapa Gado de Leite. Juiz de Fora. FAO. Brasília. pp.189-204.

Castelo Branco, J. da F. 2001. Macronutrientes em solos e pastagens nativas da região norte do estado do Piauí. Dissertação (Mestrado). Universidade Federal do Piauí. Teresina. 42 pp.

Cunha, G.C., Grendene, L.A., Durlo, M.A. e Bressan, D.A. 1993. Dinâmica nutricional em floresta decidual com ênfase aos minerais provenientes da decomposição da serapilheira. Ciência Florestal, 3: 35-64.

Embrapa. 1989. Relatório técnico anual da Unidade de Pesquisa de Âmbito Estadual de Teresina,
1981-1988. EMBRAPA-Uepae. Teresina. 238 pp.

Giraldo, L.A., Botero, J., Saldarrieaga, J. e David, P. 1995. Efecto de três densidades de arboles en el potencial forrajero de um sistema silvipastoril natural, en la região Atlantica de Colombia. Agroferesteria en Las Américas, 8: 14-19.

Justiniano, M.J. and Fredericksen, E. 2000. Phenology of tree species in Bolivian dry forests. Biotropica, 32: 276-281.

Kirmse, R.D. 1984. Effects of clearcutting on forage production, quality and decomposition in the caatinga woodland of Northeastern Brazil: implications to goat and sheep nutrition. Ph.D. Thesis. Utah State University. Logan, USA. 150 $\mathrm{pp}$.

König, F.G., Brun, E.J., Schumacher, M.V.e Seling, I. 2002a. Avaliação da sazonalidade da produção de serrapilheira numa floresta decidual no município de Santa Maria-RS. Rev Árvore, 26: 429-435.

König, F.G., Brun, E.J., Schumacher, M.V. e Jonas, L. 2002b. Devolução de nutrientes via serrapilheira em um fragmento de floresta estacional decídua no município de Santa Maria, RS. Brasil Florestal, 74: 45-52.

Leprun, J.C. 1986. Relatório de fim de convênio de manejo e conservação do solo no Nordeste brasileiro (1982-1983). SUDENE-DRN/OutreMer. O.R.S.T.O.M. Recife. 271 pp.

Machado, I.C.S., Barros, L.M. and Sampaio, E.V.S.B. 1997. Phenology of caatinga species of Serra Talhada, PE. Northeastern Brazil. Biotropica, 29: 57-68.

Menezes, R.S.C., Salcedo, I.H. and Elliott, E.T. 2002. Microclimate and nutriente dynamics in a silvopastoral system of semiarid northeastern Brazil. Agroforest Syst, 56: 27-38.

Nascimento, M. do P.S.C.B., Oliveira, M.E.A., Nascimento, H.T.S., Carvalho, J.H., Alcoforado Filho, F.G. e Santana, C.M.M. 1996. Forrageiras da Bacia do Parnaíba: usos e composição química. EMBRAPA-CPAMN/Teresina. Associação Plantas do Nordeste/Recife. EMBRAPA-CPAMN. Documentos, 19. 86 pp.

Oliveira, M.E. 1999. Influência de árvores das espécies nativas Dipteryx alata Vox e Caryocar 
MACHADO, BEZERRA NETO, NASCIMENTO, SILVA, BARRETO, NASCIMENTO E LEAL

brasiliense Camb. no sistema solo-planta em pastagem de Brachiaria decumbens Stapf. no cerrado. Tese (Doutorado). Departamento de Ecologia. Instituto de Ciências Bilógicas. UNB. Brasília-DF. 104 pp.

Pott, A. 1993. Árvores no sistema pastoril. Simpósio sobre usos múltiplos de leguminosas arbóreas e arbustivas, 1. Anais... Instituto de Zootecnia. Nova Odessa, SP. pp. 95-129.

Ramos, G.M. 1994. Recomendações práticas para o cultivo do guandu para produção de feno. EMBRAPA-CPAMN. Teresina. EMBRAPA, CPAMN. Circular Técnica, 13.16 pp.
Sampaio, E.V.S.B., Nunes, K.S. e Lemos, E.E.P. 1988. Ciclagem de nutrientes na mata de Dois Irmãos (Recife-PE) através da queda de material vegetal. Pesqui Agropecu Bras, 23: 10551061.

Sampaio, I.B.M. 1998. Estatística aplicada a experimentação animal. Fundação de Ensino e Pesquisa em Medicina Veterinária e Zootecnia. Belo Horizonte. 221 pp.

Silva, J.E. e Resck, D.V.S. 1998. Matéria orgânica do solo. In: Vargas, M.A.T. e Hungria, M. (Eds.). Biologia dos solos do cerrado. Embrapa-CPAC. Planaltina. pp. 465-524. 